Revista de Economia Política, vol. 22, $n^{\circ} 1$ (85), pp. 3-23, janeiro-março/2002

\title{
Neomonetarismo Tropical: A Experiência Brasileira nos Anos Noventa*
}

\author{
Tropical Neomonetharism: \\ The Brazilian Experience in the Nineties
}

ALFREDO SAAD FILHO $* *$
LECIO MORAIS $* * *$

RESUMO: Este artigo analisa o desempenho da economia brasileira durante os anos 90, à luz da mudança de política neomonetarista implementada de maneira desigual, mas incremental, ao longo desta década. O artigo mostra que essa mudança de política foi associada a, e contribuiu para, uma mudança na estrutura da indústria de transformação, a deterioração financeira do setor público, o aperto da restrição da balança de pagamentos e o aumento da dependência econômica externa. Essas mudanças estruturais foram em grande parte responsáveis pela crise cambial de 1999. As medidas políticas subsequentes falharam amplamente em lidar com essas fraquezas da economia brasileira.

PALAVRAS-CHAVE: Brasil; neoliberalismo; neomonetarismo; dependência; liberação financeira.

ABSTRACT: This paper reviews the performance of the Brazilian economy during the 1990s, in the light of the neomonetarist policy shift implemented unevenly but incrementally across this decade. The paper shows that this policy shift was associated with, and contributed to, a change in the structure of manufacturing industry, the financial deterioration of the public sector, the tightening of the balance of payments constraint, and increasing external economic dependence. These structural changes were largely responsible for the currency crisis of 1999. Subsequent policy measures have largely failed to address these weaknesses of the Brazilian economy.

KEYWORDS: Brazil; neoliberalism; neomonetarism; dependency; financial liberalization. JEL Classification: B24; B51.

\footnotetext{
* Somos gratos pelos comentários de Philip Arestis, Maria Amarante Baracho, Luiz Carlos Bresser-Pereira, Gary Dymski, Ben Fine, Maria de Lourdes Mollo, Bruno Saraiva Malcolm Saywer, Marcio Valença e Howard Walker. Este projeto de pesquisa foi apoiado pela Nuffield Foundation (SGS/LB/203).

* Department of Development Studies - SOAS, University of London, Londres, Inglaterra. E-mail: ad59@soas.ac.uk; Orcid: 0000-0002-6625-2273.

** Câmara dos Deputados, Brasília/DF, Brasil. E-mail: leciomorais@gmail.com; Orcid: 0000-00025934-2828.
} 
Este artigo analisa a trajetória e as mudanças estruturais ocorridas na economia brasileira durante os anos noventa. Essa foi uma década notável devido, em parte, às taxas de crescimento excepcionalmente baixas no período ${ }^{1} \mathrm{e}, \mathrm{em}$ parte, às mudanças no modo de acumulação da economia brasileira ${ }^{2}$. A principal mudança foi o abandono da industrialização pela substituição de importações (ISI) por um novo modo de acumulação baseado na microintegração da base produtiva e do capital financeiro em circuitos transnacionais. Essa mudança foi justificada de duas maneiras. Primeiro, ao final dos anos oitenta, a maioria dos analistas argumentava que a ISI brasileira enfrentava três problemas insuperáveis: a crise fiscal do Estado, a suposta ineficiência dos setores manufatureiro e de serviços (especialmente o setor financeiro, estruturalmente incapaz de canalizar poupanças domésticas para investimentos de longo prazo), e a dificuldade para criar um sistema nacional de inovações suficientemente dinâmico. Por essas razões, as taxas de crescimento econômico declinaram, e a inflação acelerou, até o bloqueio do processo de acumulação após a crise da dívida externa em 1982 (Bresser-Pereira 1996a, Fiori 1992).

A seguir, no início dos anos noventa, um novo consenso emergiu gradualmente na elite brasileira. Acreditava-se que as políticas econômicas neomonetaristas associadas com o "Consenso de Washington" e a predominância do setor financeiro sobre os interesses industriais proporcionavam a única perspectiva de crescimento sustentável (Fine \& Saad Filho 1999). Essa mudança estratégica foi estimulada pelas fortes pressões de Washington, e validada pela receptividade dos capitais brasileiros e estrangeiros, e pela performance aparentemente excepcional de países como Argentina, México e Coréia do Sul.

O sucesso da nova política econômica dependia da captação de vultosos recursos reais e financeiros no exterior. No início dos anos noventa, esses recursos puderam ser obtidos com relativa facilidade devido à excepcional liquidez dos mercados financeiros internacionais, e às baixas taxas de juro. Apesar de sucessos significativos, em particular a eliminação da alta inflação, o rápido aumento da produtividade no setor manufatureiro e (dependendo do ponto de vista) elevados superávits fiscais, as políticas neomonetaristas não conseguiram, até o momento, levar ao crescimento rápido e sustentado, e elas desestabilizaram o sistema produtivo e o balanço de pagamentos.

O novo modo de acumulação é muito vulnerável a flutuações da liquidez internacional e do custo de captação dos recursos externos. Esta vulnerabilidade foi a principal causa do aumento das taxas de juro domésticas (overnight) de $12 \%$ ao ano, entre junho de 1990 e dezembro de 1991 (quando o grau de liberalização era relativamente pequeno) para 23\% entre janeiro de 1992 e maio de 1994 (antes do Plano Real), e 24\% entre julho de 1994 e dezembro de 1998 (durante o Plano Real).

\footnotetext{
${ }^{1}$ Em 1981-89, a chamada "década perdida”, o PIB brasileiro cresceu, em média, 2,2\% anuais. Esse re-sultado foi melhor que o da década seguinte, quando o PIB cresceu apenas 1,7\% ao ano.

${ }^{2} \mathrm{O}$ modo de acumulação reflete as estruturas econômicas e arranjos institucionais específicos ao processo de acumulação de capital em uma determinada região, em certo período (Fine \& Rustomjee 1996)
} 
Essas altas taxas de juro são importantes causas da performance desapontadora da economia ao longo da última década, e do desequilíbrio fiscal do governo central ${ }^{3}$. Em resumo, a turbulência financeira internacional demonstrou que as políticas neomonetaristas aumentaram a vulnerabilidade da economia a flutuações do financiamento externo, tornando os custos de transição ao novo modo de acumulação muito maiores do que havia sido antecipado. Isso foi demonstrado pelo impacto das crises financeiras no México, Sudeste da Ásia e Rússia, que culminaram, no Brasil, com a crise cambial de janeiro de 1999.

Este artigo discute a natureza, impacto e custos do neomonetarismo no Brasil em sete seções. A primeira expõe os fundamentos do neomonetarismo e as limitações dessa política econômica. A segunda analisa a virada neomonetarista no Brasil no início dos anos noventa. A terceira demonstra que o neomonetarismo aumentou a vulnerabilidade externa da economia brasileira, e que eventos externos tiveram um papel importante na crescente fragilidade deste modo de acumulação. A quarta explica as mudanças no modo de concorrência como resultado da experiência neomonetarista. A quinta analisa o impacto monetário, financeiro e fiscal do neomonetarismo. A sexta recapitula as causas e conseqüências da crise cambial de janeiro de 1999. Por fim, a sétima analisa criticamente as políticas implementadas após a desvalorização do real. A conclusão sumaria os principais argumentos deste artigo.

\section{NEOMONETARISMO GLOBAL}

Os traços essenciais do neomonetarismo foram identificados por Arestis \& Sawyer (1998). Essa política tem vários traços em comum com o Consenso de Washington, e ela pode ser analisada em dois níveis. Em nível microeconômico, o neomonetarismo presume que numa economia descentralizada e desregulamentada a livre-concorrência leva rapidamente ao equilíbrio de pleno emprego (as implicações da teoria do "second best" são ignoradas). Por conseqüência, primeiro, os mercados (especialmente financeiros), em lugar do Estado, devem equacionar problemas como a especialização internacional do país, a competitividade industrial, a geração de empregos e, mais geralmente, controlar as fontes da melhoria do bemestar da população. Segundo, as políticas industriais "verticais" ou setoriais devem ser evitadas, pois elas modificam sistematicamente os preços relativos e a alocação de recursos de formas que podem não ser aceitáveis para os mercados (financeiros); ver Chang (1994) e Nembhard (1996).

Em nível macroeconômico, o neomonetarismo é pragmaticamente baseado no avanço da "globalização", que é geralmente definida de forma superficial, como se ela fosse simples e inevitável (Radice 1998, 1999). Argumenta-se que a globalização

\footnotetext{
${ }^{3}$ O governo central inclui o Governo Federal (Tesouro Nacional), a Previdência Social e o Banco Central do Brasil. Os governos subnacionais, empresas estatais e autarquias federais (exceto a Previdência Social) são incluídos no setor privado, pois têm autonomia financeira e não dispõem de poder emissor.
} 
aumenta a liquidez do capital produtivo e financeiro transnacional e sua sensibilidade às políticas nacionais. Isso implica que os países podem atrair grandes fluxos de capital estrangeiro para suplementar a poupança e o investimento doméstico, e obter novas tecnologias e acesso aos mercados externos. Entretanto, eles também podem enfrentar saídas de capital insustentáveis, dependendo das políticas governamentais. Evidentemente, as entradas de capital serão maiores, mais rápidas e mais duradouras quanto mais próximas as políticas domésticas forem do "identikit" neomonetarista, incluindo equilíbrio fiscal, liberalização comercial e da conta de capitais, desregulamentação dos mercados de produtos e fatores, e privatização (para uma crítica, ver Grabel 2000 e Palley 2000).

A ferramenta mais importante no arsenal neomonetarista é a taxa de juros. Taxas de juro "corretas" supostamente podem ajudar a atingir níveis sustentáveis de poupança e investimento, equilíbrio do balanço de pagamentos e baixa inflação simultaneamente e, portanto, elevado crescimento no longo prazo. Essas políticas implicam que as taxas de juro domésticas são geralmente mais elevadas do que elas seriam num regime alternativo, no qual objetivos similares seriam buscados através de um conjunto mais amplo de políticas. Obviamente, taxas de juro elevadas tendem a reduzir os níveis de emprego, investimento, produto e renda relativamente ao que eles seriam num cenário alternativo, tanto no curto como no longo prazo. Mais especificamente, o desemprego estrutural tende a aumentar porque a capacidade tende a se esgotar, e a restrição externa torna-se rígida, antes que o desemprego caia substancialmente. Normalmente se espera que as poupanças externas anulem o impacto depressivo das altas taxas de juro, mas esta presunção não foi substanciada empiricamente (Calvo et al. 1993, 1996).

Apesar dessas limitações, as reformas neomonetaristas podem ser suficientes para gerar estabilidade macroeconômica e crescimento no curto prazo porque elas são parte do senso comum atual e, portanto, têm credibilidade por definição (Arestis \& Glickman, no prelo). Além disso, se a liquidez internacional é elevada e as taxas de juro são baixas, como no início dos anos noventa, a liberalização comercial e da conta de capitais parece abolir a restrição externa. Tais liberalizações podem atrair fluxos de capital suficientes para financiar um déficit comercial elevado, que permite o aumento do consumo, do investimento e das taxas de crescimento econômico, num círculo virtuoso que pode durar vários anos.

\section{A MUDANÇA DE POLÍTICA}

A atração de recursos reais e financeiros do resto do mundo foi um dos objeti-vos mais importantes das reformas neomonetaristas no Brasil. Em 1988, foi reformado o sistema financeiro doméstico e, no ano seguinte, iniciada a liberalização dos fluxos de capital (Studart 1999b). O regime cambial foi gradualmente flexibilizado a seguir (Banco Central do Brasil 1993), enquanto as restrições à importação foram gradualmente reduzidas desde 1990. A partir do final de 1991, sucessivos governos adotaram políticas monetárias contracionistas para controlar a demanda 
e a inflação, atrair capital externo e gerar excedentes exportáveis. Por fim, um amplo programa econômico neomonetarista foi implementado em meados dos anos noventa, sob o disfarce do Plano Real.

Essas políticas neomonetaristas estão associadas com uma mudança substancial do papel econômico do Estado. Políticas de desenvolvimento setorial foram abandonadas, e o Estado "liberalizou" e "desregulamentou" a economia. Agências federais como o BNDES, o Banco Central e o Tesouro Nacional organizaram, promoveram e financiaram a privatização das maiores empresas estatais, e sua integração em conglomerados brasileiros e transnacionais. Esperava-se que a integração entre capitais nacionais e estrangeiros no nível microeconômico assegurasse o desenvolvimento em harmonia com a "economia global". Essas políticas tiveram sucesso parcial. Em 1992-93, apesar da instabilidade política e da elevada inflação, o fluxo de capitais privados se restabeleceu, a entrada de bens importados transformou as perspectivas de consumo, e a economia voltou a crescer.

Para avaliarmos o impacto das políticas neomonetaristas, vamos definir as transferências de recursos reais e financeiros e o impacto monetário do setor externo.

As transferências de recursos reais (TR) são iguais ao saldo comercial de bens e serviços não-fatores. Se TR > 0, o país transfere recursos reais (minério de ferro, aço, suco de laranja, farelo de soja etc.) ao resto do mundo. A essas transferências correspondem entradas de divisas, que podem ser acumuladas nas reservas internacionais ou gastas através de transferências de recursos financeiros ao resto do mundo. Por outro lado, se o país é importador líquido de bens e serviços os residentes recebem transferências de recursos reais do exterior (incluindo máquinas, petróleo, fretes e turismo), TR $<0$. Nesse caso, o equilíbrio do balanço de pagamentos exige a simultânea transferência de recursos financeiros do resto do mundo (por exemplo, investimentos estrangeiros ou novos empréstimos) para proporcionar as divisas necessárias para cobrir os compromissos externos.

As transferências de recursos financeiros (TF) incluem os fluxos financeiros unilaterais (FU) e os fluxos da dívida externa (FD). FU incluem os fluxos líquidos de investimentos diretos e de portfólio, as remessas de lucros e dividendos, o pagamento de outros serviços de fator, as transferências unilaterais e os erros e omissões no balanço de pagamentos. FD incluem os desembolsos de novos empréstimos e o pagamento do serviço da dívida (juros e amortizações) pelo setor privado e o governo central.

Se o setor privado tem que repassar suas divisas ao Banco Central, transações externas privadas afetam o passivo primário do governo central (base monetária mais dívida mobiliária do Tesouro e do Banco Central, DMF). As entradas de divisas expandem a base monetária ou, caso esterilizadas, a DMF; por outro lado, saídas de divisas contraem o passivo primário. As transações do governo central são diferentes. Se o governo central toma empréstimos externos ou emite bônus soberanos (ou paga o serviço de sua dívida externa), o passivo primário fica inalterado; apenas o estoque de reservas se modifica. Por outro lado, se alguma agência do governo central tomar recursos externos para financiar investimentos ou despesas correntes, a entrada de divisas afeta o passivo primário apenas através do aumento do déficit fiscal, quando 
o equivalente em moeda doméstica for gasto (o pagamento do empréstimo reduz o déficit fiscal). Neste artigo, o impacto monetário do setor externo é o valor em moeda doméstica das transações externas do setor privado.

Esses conceitos permitem a avaliação mais precisa do impacto do neomonetarismo (ver tabela 1). Em 1990-91, o Brasil remeteu recursos reais ao exterior no valor de US\$15,7 bilhões. O correspondente influxo de divisas foi usado para financiar o serviço da dívida externa, US $\$ 14,4$ bilhões, e saídas unilaterais de US $\$ 1,1$ bilhão. $\mathrm{O}$ balanço de pagamentos do Brasil mudou substancialmente no período seguinte. Entre a liberalização da conta de capitais, em 1992, e o primeiro semestre de 1994 (antes do Plano Real), a transferência de recursos reais ao exterior atingiu US $\$ 27,7$ bilhões. Novos empréstimos e a renegociação da dívida externa levaram a fluxos da dívida positivos em US $\$ 2,6$ bilhões, enquanto os fluxos financeiros unilaterais atingiram US $\$ 11,4$ bilhões (especialmente devido a investimentos externos de US\$15,6 bilhões). O superávit acumulado do balanço de pagamentos atingiu US $\$ 41,6$ bilhões, e as reservas internacionais cresceram de US\$9,4 bilhões para US $\$ 42,9$ bilhões. O impacto monetário do setor externo foi fortemente expansionista, em US\$41,4 bilhões.

Tabela 1

Brasil: Balanço de pagamentos, variáveis selecionadas, 1990-1999 (US\$ milhões).

\begin{tabular}{|c|c|c|c|c|c|c|}
\hline & \multirow{2}{*}{$\begin{array}{c}\text { Transferência } \\
\text { de recursos } \\
\text { reais (a) }\end{array}$} & \multicolumn{3}{|c|}{ Transferências financeiras } & \multirow{2}{*}{$\begin{array}{c}\text { Balanço de } \\
\text { pagamentos } \\
(\mathrm{e}=\mathrm{a}+\mathrm{d})\end{array}$} & \multirow{2}{*}{$\begin{array}{c}\text { Impacto } \\
\text { monetário } \\
\text { do setor } \\
\text { externo (f) }\end{array}$} \\
\hline & & $\begin{array}{l}\text { Fluxos da } \\
\text { dívida } \\
\text { externa (b) }\end{array}$ & $\begin{array}{c}\text { Fluxos } \\
\text { unilaterais (c) }\end{array}$ & $\begin{array}{c}\text { Total } \\
(d=b+c)\end{array}$ & & \\
\hline $\begin{array}{l}\text { 1990. I-1991.IV } \\
\text { (8 trim.) }\end{array}$ & $15.672,7$ & $-14.388,5$ & $-1.136,1$ & $-15.524,6$ & 148,1 & $-4.873,2^{*}$ \\
\hline $\begin{array}{l}\text { 1992.I-1994.II } \\
\text { (10 trim.) }\end{array}$ & $27.654,5$ & $2.566,8$ & $11.411,0$ & $13.977,8$ & $41.632,3$ & $41.365,3$ \\
\hline $\begin{array}{l}\text { 1994.III-1995.I } \\
\text { (3 trim.) }\end{array}$ & $-2.310,1$ & $-3.710,0$ & $-2.941,7$ & $-6.651,7$ & $-8.961,8$ & $-6.504,9$ \\
\hline $\begin{array}{l}\text { 1995.II-1998.II } \\
\text { (13 trim.) }\end{array}$ & $-39.181,9$ & $32.307,7$ & $45.513,1$ & $77.820,8$ & $38.638,9$ & $49.110,7$ \\
\hline $\begin{array}{l}\text { 1998.III-1999.I } \\
\text { (3 trim.) }\end{array}$ & $-10.788,3$ & $-45.433,2$ & $8.018,9$ & $-37.414,3$ & $-48.202,6$ & $-43.994,4$ \\
\hline $\begin{array}{l}\text { 1999.II-1999.IV } \\
\text { (3 trim.) }\end{array}$ & $-3.919,9$ & $-14.720,0$ & $21.265,9$ & $6.545,9$ & $2.626,0$ & n.d. \\
\hline
\end{tabular}

a: Superávit comercial (bens e serviços).

b: Novos empréstimos menos juros e amortizações pagos.

c: Fluxos líquidos de investimentos diretos e de portfolio, remessas de lucro e dividendos, outros serviços de fator, transferências unilaterais e erros e omissões no balanço de pagamentos.

*: 1991.

Fonte: Calculado a partir do Boletim do Banco Central. 
Nesse meio-tempo, as taxas de inflação cresceram regularmente. A eliminação da alta inflação tornou-se essencial para a legitimação política e a viabilidade econômica da estratégia de acumulação neomonetarista.

A alta inflação foi eliminada através do Plano Real ${ }^{4}$. Esse plano incorporava uma interpretação inercialista da inflação brasileira, segundo a qual políticas contracionárias são necessárias mas insuficientes para reduzir a inflação; a desindexação coordenada pelo Estado é também essencial ${ }^{5}$. O Plano Real incluiu três elementos principais, a reforma fiscal, a eliminação da indexação, e a introdução de uma nova moeda. A estabilização foi reforçada, mais tarde, pela liberalização comercial, a sobrevalorização da moeda, e por uma ampla gama de políticas neomonetaristas (ver seção 3). A síntese entre a desinflação, a liberalização comercial e as demais políticas neomonetaristas foi inicialmente bem-sucedida. A inflação caiu rapidamente, a demanda agregada expandiu, e o país parecia pronto a retomar o crescimento acelerado com base em investimentos estrangeiros e no aumento da produtividade.

\section{TURBULÊNCIA EXTERNA E VULNERABILIDADE BRASILEIRA}

Apesar desses sucessos, as políticas neomonetaristas são potencialmente desestabilizadoras por quatro razões.

Primeiro, os fluxos de capital aos países periféricos geralmente são mais sensíveis às circunstâncias dos mercados financeiros dos países centrais que às políticas macroeconômicas dos países recipientes. Portanto, a liberalização comercial e da conta de capitais aumenta a vulnerabilidade da economia a flutuações da liquidez internacional e do custo dos recursos externos, porque o país torna-se estruturalmente mais dependente do capital estrangeiro (ver seção 6 e Bird 1996, Calvo et al. 1996, Chang 1999 e Palma 1998).

Segundo, a liberalização financeira e da conta de capitais é desestabilizadora porque ela necessariamente aumenta a taxa de juros doméstica e a fragilidade financeira doméstica (as taxas de juro no Brasil aumentaram substancialmente após a liberalização da conta de capitais em 1992, ver figura 1 e seção 5). A fragilidade financeira e os custos devidos às altas taxas de juro, especialmente o serviço da DMF, podem ser reduzidos, mas não eliminados inteiramente, por melhorias na supervisão e fiscalização financeira (Arestis \& Demetriades 1999).

\footnotetext{
${ }^{4}$ Governo do Brasil (1993); ver Dornbusch (1997), Nogueira Batista (1996) e Saad Filho \& Maldonado Filho (1998).

${ }^{5}$ Para as análises originais, ver Bresser-Pereira (1981, 1996b), Bresser-Pereira \& Nakano (1983, 1985); ver ainda Mollo \& Saad Filho (2001).
} 


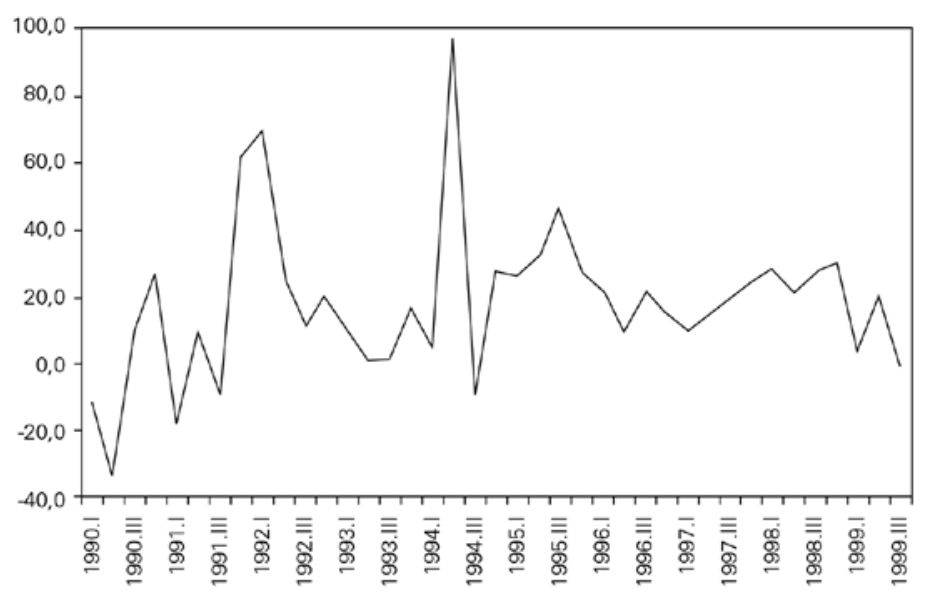

* Taxas Selic (overnight) trimestrais anualizadas, deflacionadas pelo IGP-DI.

Fonte: Boletim do Banco Central.

Terceiro, fluxos de capital estrangeiro tendem a (sobre)valorizar a moeda. Essa (sobre)valorização é freqüentemente justificada pelo estímulo ao aumento da produtividade e a necessidade de estabilizar as reservas internacionais sem impor restrições aos fluxos de capital. Entretanto, a sobrevalorização aumenta a necessidade de taxas de juro reais elevadas, em parte para esterilizar os fluxos de capital e, em parte, para financiar o déficit comercial, o que tem um impacto cumulativo sobre o déficit público e a fragilidade financeira do setor privado (ver abaixo).

Quarto, altas taxas de juro estimulam a acumulação de dívida externa e criam espaço para a arbitragem através da tomada de empréstimos externos para aplicações financeiras domésticas, especialmente em títulos públicos (ver seção 5).

Vamos agora avaliar a implementação dessas políticas no Brasil após o Plano Real (ver Saad Filho \& Morais 2000). A seção 2 indicou que a abertura da conta de capitais atraiu grandes fluxos financeiros unilaterais para o Brasil, levando à rápida acumulação de reservas internacionais. No primeiro semestre de 1994, a elevada liquidez internacional e as altas taxas de juro domésticas contribuíram para um significativo aumento dos fluxos de capital, levando a transferências financeiras para o Brasil de US\$11,8 bilhões. Esses fluxos, e o apoio do governo à valorização da moeda, foram os principais responsáveis pela sobrevalorização cambial. Em termos efetivos reais, a moeda nacional ganhou $16 \%$ no segundo semestre de 1994 e, entre julho e outubro, o dólar caiu de $\mathrm{R} \$ 1$ para apenas $\mathrm{R} \$ 0,82 .{ }^{6}$

Em meados de 1994, parecia que esses fluxos de capital seriam suficientes

\footnotetext{
${ }^{6}$ Bacha (1997, p. 201), Dornbusch (1997, p. 375), Kilsztajn (1996) e Nogueira Batista (1996, p. 34) apresentam estimativas da sobrevalorização do Real.
} 
para financiar os compromissos externos do Brasil, mesmo na ausência de transferências de recursos reais ao resto do mundo. Ao mesmo tempo, a liberalização comercial tornou-se muito importante por três razões. Primeiro, ela reduziria o poder de mercado dos oligopólios e do movimento sindical, e ampliaria a oferta de bens de consumo e investimento, o que deveria aumentar a produtividade e contribuir para a queda da inflação. Segundo, ela forçaria a indústria doméstica a investir em novas tecnologias, levando ao crescimento econômico e ao aumento do nível de emprego. Terceiro, ela reduziria o superávit comercial e, portanto, o impacto monetário do setor externo, que ajudaria a conter o crescimento da DMF e da conta de juros do governo. Em resumo, enquanto as políticas domésticas tivessem "credibilidade", poupanças externas baratas financiariam a acumulação rápida e sustentada de capital. O governo abandonou sua estratégia gradualista no segundo semestre de 1994. Grande parte dos incentivos à exportação foram abandonados, as importações foram drasticamente liberalizadas, e as autoridades assentiram à sobrevalorização do real para eliminar o superávit comercial:

[A] lógica da política cambial é produzir redução nas exportações, aumento das importações, déficit em conta corrente no balanço de pagamentos e, portanto, retornar o país a importador de capitais. Essa importação, junto com a poupança interna, acumulada pelo setor privado, é que vai financiar o crescimento econômico (Pedro Malan, presidente do Banco Central e futuro Ministro da Fazenda, Gazeta Mercantil, 24/10/94)

Essas políticas foram bem-sucedidas. As transferências de recursos reais ao exterior caíram drasticamente, de US $\$ 8,3$ bilhões (ou seja, um superávit comercial) nos primeiros três trimestres de 1994, para menos US\$9,1 bilhões (um déficit) nos três trimestres seguintes. Infelizmente para o governo brasileiro, a liquidez internacional reduziu-se fortemente em meados de 1994. Entre maio e dezembro, o FED elevou seis vezes a taxa de desconto, que passou de 3 para $4,75 \%$ ao ano. $\mathrm{O}$ aumento dos juros internacionais reverteu os fluxos de capital, e dificultou o financiamento dos déficits correntes de vários países ditos “emergentes”. No final do ano, era evidente que as reservas de divisas de alguns países estavam minguando, enquanto seus déficits correntes mantinham-se elevados. Começou, então, a fuga em massa que levou à crise do México na virada do ano (seu impacto no Brasil pode ser visto na tabela 1), e a severos abalos na Argentina. Fugas semelhantes ocorreram após as crises asiática, em 1997, e russa, em 1998 (ver seção 6).

Após esses episódios, os mercados financeiros internacionais tornavam-se temporariamente refratários ao financiamento dos déficits correntes dos países periféricos. Essas mudanças dos fluxos internacionais de capital desestabilizaram a estratégia de acumulação neomonetarista no Brasil. O regime cambial finalmente mudou em março de 1995, quando bandas deslizantes foram introduzidas, inicialmente com o dólar cotado a $\mathrm{R} \$ 0,86-0,90$. A intenção do governo era desvalorizar o real em torno de meio ponto percentual além da taxa de inflação mensal, para aumentar a competitividade das exportações e reduzir o déficit corrente. Foram 
também introduzidas medidas administrativas para limitar as importações de bens de consumo, e os incentivos à exportação foram parcialmente restaurados (Banco Central do Brasil 1995, p. 103).

Essas medidas melhoraram a balança comercial, mas não eliminaram as transferências de recursos reais para o Brasil. Além disso, o governo foi incapaz de elaborar uma estratégia de financiamento do balanço de pagamentos no longo prazo, especialmente no caso de flutuações acentuadas da liquidez internacional. Apesar da vulnerabilidade do balanço de pagamentos, o retorno da liquidez internacional em 1995 pareceu confirmar as esperanças do governo. As transferências de recursos financeiros atingiram US $\$ 25,0$ bilhões nos três últimos trimestres de 1995 , e as reservas internacionais do Brasil aumentaram de US\$18,1 bilhões para US\$51,8 bilhões (ver tabela 1). As altas taxas de juro domésticas ampliaram as oportunidades para ganhos especulativos no open market, especialmente devido à desaceleração do crescimento. Eventualmente, as altas taxas de juro desestabilizaram as finanças do governo central e dos governos subnacionais e o sistema bancário, levando a uma aguda crise fiscal e financeira (ver seção 5).

\section{O NOVO MODELO COMPETITIVO}

As políticas neomonetaristas introduziram um novo modelo competitivo na economia, baseado na micro-integração dos setores produtivo e financeiro em circuitos internacionais do capital. Era esperado que a intensa competição externa levasse a parcerias, fusões e aquisições ou ao colapso das firmas supostamente ineficientes, elevando a produtividade média da economia (ver seção 2 ).

O neomonetarismo teve um impacto ambíguo sobre a indústria manufatureira, apesar do elevado investimento estrangeiro (o estoque de investimento direto dobrou para US\$90 bilhões entre 1994-98, enquanto o investimento de portfólio cresceu de US $\$ 25$ bilhões para US $\$ 60$ bilhões). Primeiro, a proporção de produtos manufaturados importados cresceu muito (ver tabela 2).

Segundo, estima-se que firmas estrangeiras participaram de 49,1\% das 3.276 fusões e aquisições e compras de participação minoritária em empresas nacionais registradas no Brasil entre 1991 e 1999. Tanto o número de operações quanto a participação estrangeira cresceram continuamente após 19917. Os setores mais afetados pela penetração das empresas transnacionais foram os de material elétrico, eletrônico e de telecomunicações, autopeças e produtos alimentícios. Nesses e em outros setores, grandes empresas de capital nacional (inclusive com atuação transnacional), como a Metal Leve, Lacta, Cofap, Freios Varga, Arno, Refripar, Renner, Agroceres e os bancos Nacional, Garantia, Bamerindus e Real, foram absorvidos por conglomerados estrangeiros

\footnotetext{
${ }^{7}$ Ver relatório da Price Waterhouse Coopers (Folha de S. Paulo, 21/1/00, p. 2-1). Para estimativas de ordem semelhante, ver Gonçalves (1999a: 138-42).
} 
Brasil: Coeficientes de importação da indústria manufatureira, 1993 e 1996 (\%).

\begin{tabular}{|c|c|c|}
\hline Setor & 1993 & 1996 \\
\hline 1. Bens de capital seriados e produtos eletrônicos & 29 & $65-75$ \\
\hline 2. Matérias-primas químicas, fertilizantes, resinas & $20-26$ & $33-42$ \\
\hline 3. Autopeças, têxteis naturais, bens de capital por encomenda, borracha & $8-15$ & $20-25$ \\
\hline $\begin{array}{l}\text { 4. Farmacêutica, não-ferrosos, tratores, eletroeletrônicos domésticos, } \\
\text { vidro, produtos químicos diversos }\end{array}$ & $7-11$ & $13-16$ \\
\hline $\begin{array}{l}\text { 5. Têxteis sintéticos, eletrodomésticos, petroquímicos intermediários, veí- } \\
\text { culos, alimentos, papel e papelão }\end{array}$ & 3-6 & $9-12$ \\
\hline $\begin{array}{l}\text { 6. Bebidas, calçados, plásticos, laticínios, higiene e limpeza, alimentos } \\
\text { semi-processados }\end{array}$ & $0.7-3$ & $4-8$ \\
\hline 7. Produtos não-transacionáveis (cimento, matérias-primas, e outros) & $0.5-2.5$ & $1-4$ \\
\hline
\end{tabular}

Fonte: Coutinho, Baltar \& Camargo (1999, p. 70).

O crescimento da participação estrangeira contribuiu para os ganhos de produtividade, especialmente na indústria manufatureira. O novo modelo competitivo influenciou esse processo em diversos níveis. Primeiro, ele induziu uma mudança nas técnicas gerenciais rumo a métodos "modernos" ligados ao "downsizing" da força de trabalho, inclusive no segmento gerencial. Segundo, a tendência de aumento do desemprego industrial foi reforçada pela introdução de novas tecnologias poupadoras de mão-de-obra. Terceiro, as firmas tenderam a simplificar seus produtos e reduzir o valor adicionado local para obter ganhos de eficiência. Em parte por essas razões, a produtividade manufatureira cresceu em média $7,6 \%$ ao ano entre 1990 e 1997 (Feijó \& Carvalho 1998).

Esse processo teve um impacto espacial diferenciado. Zonas manufatureiras tradicionais perderam acentuadamente, especialmente a Grande São Paulo, enquanto regiões tradicionalmente associadas a outras atividades econômicas ganharam, em particular no Sul e Nordeste do país. Mais de um milhão de empregos industriais foram eliminados no Brasil entre 1989 e 1997, o que corresponde a mais de um terço do total (Bonelli 1999, p. 89), e a taxa de desemprego aberto no país cresceu de 3,9\% em dezembro de 1990 para 8,6\% em junho de 1998, segundo o IBGE ${ }^{8}$. Coutinho, Baltar \& Camargo (1999, pp. 66, 73) corretamente concluem que:

[A] saída do Estado como gestor de políticas de desenvolvimento industrial ou mesmo de ator desse processo contribuiu fortemente para elevar o grau de exposição da indústria doméstica aos bens importados [...]

\footnotetext{
${ }^{8}$ Os dados do IBGE tendem a subestimar as taxas de desemprego. Segundo o Dieese, o desemprego total em São Paulo atingiu 20,3\% em abril de 1999. Para uma excelente análise da desestruturação recente dos mercados de trabalho no Brasil, ver Pochmann (1999).
} 
a explosão das importações implicou rápido esvaziamento das cadeias produtivas, provocando forte diminuição do poder de impulsão da demanda intra-industrial e de alavancagem dos demais setores, redundando em forte redução da capacidade de criação de empregos na economia [...] [A] busca frenética por redução de custos implica rodadas sucessivas de racionalização e inovações no processo produtivo, com forte aumento das tensões sobre o mercado de trabalho [...] [O]perando com coeficientes mais elevados de insumos e componentes importados (portanto com nível significativamente mais baixo de agregação de valor no país), os efeitos sobre a geração interna de demanda por bens intermediários e sobre a criação de empregos tenderão [...] a ser bastante modestos.

Os projetos de investimento recentes geralmente reproduzem essas características, e tendem a ter baixa propensão a exportar:

[A] grande maioria dos projetos de investimento [doméstico] foi motivada pela forte expansão do mercado interno [em 1994-95], sendo pouco expressivo o componente exportador deles. Também com relação aos investimentos estrangeiros, verifica-se que o mercado brasileiro é o principal alvo dos projetos em andamento (Coutinho, Baltar \& Camargo 1999, p. 72). ${ }^{9}$

\section{MOEDA, CRÉDITO E FINANÇAS}

As políticas neomonetaristas do governo brasileiro tiveram um forte impacto fiscal e financeiro, em três níveis.

Primeiro, as altas taxas de juros, as transferências de recursos dos governos subnacionais para o governo central associadas ao Plano Real, e a redução do ritmo de crescimento da arrecadação tributária, devido à estagnação associada com a crise mexicana, afetaram as finanças dos governos subnacionais, com implicações para o governo central. Entre a crise do México e o final de 1996, a dívida mobiliária dos governos subnacionais cresceu de US $\$ 28,6$ bilhões para US $\$ 48,1$ bilhões, apesar de seu déficit primário ter sido de apenas US $\$ 5,2$ bilhões. O impacto potencial da desvalorização do capital representado pelos títulos dos governos subnacionais persuadiu o governo central a trocar seus títulos por esses papéis duvidosos. Essa troca de ativos atingiu US\$84,0 bilhões em setembro de 1999.

Segundo, o setor financeiro foi enfraquecido pelo Plano Real, especialmente pela eliminação de transferências inflacionárias de aproximadamente $2,5 \%$ do PIB

\footnotetext{
${ }^{9}$ Para uma análise detalhada da evolução da produtividade, das mudanças da estrutura do emprego, do aumento da precariedade do emprego e do crescimento do desemprego durante o Plano Real, ver CNI/ Cepal (1997), Paes de Barros, Camargo \& Mendonça (1998) e Ramos \& Almeida Reis (1998). Para uma análise de longo prazo, ver Bonelli \& Gonçalves (1998) e Urani (1998).
} 
(Cysne 1994). Além disso, várias pequenas e médias instituições sofreram sérias dificuldades em 1995, em parte devido à falta de liquidez internacional e, em parte, pelo corte de liquidez implementado naquele ano. A ameaça de uma séria crise financeira foi evitada através de extensa intervenção do Banco Central, a um custo de aproximadamente US\$20 bilhões, e a reestruturação do sistema bancário ${ }^{10}$. Entre 1995 e 1997, o Banco Central interveio ou forçou a liquidação ou venda de 72 bancos dentre os 271 existentes em julho de 1994 (Barros \& Almeida Jr 1997). Seus passivos de liquidação duvidosa foram assumidos pelo Banco Central ou pelo Tesouro, ou repassados a outras instituições mediante incentivos fiscais. $\mathrm{O}$ patrimônio "sadio" remanescente foi vendido a outras instituições, especialmente estrangeiras. Como resultado, o sistema financeiro brasileiro tornou-se substancialmente mais concentrado e internacionalizado ${ }^{11}$.

Terceiro, o impacto monetário do setor externo atingiu US $\$ 32,5$ bilhões entre o segundo trimestre de 1995 e o final de 1996 (menos US\$5,7 bilhões em 1997).

Naquele período, a base monetária cresceu US $\$ 4,2$ bilhões (US $\$ 11,2$ bilhões em 1997), demonstrando que a DMF absorveu grande parte do impacto monetário do setor externo, especialmente em 1995-96. Esse impacto expansionista deveu-se, em grande medida, ao crescimento acelerado da dívida externa que, por seu lado, respondeu à busca por fontes de financiamento mais barato no exterior e à arbitragem dos juros. Essas pressões foram os principais fatores responsáveis pela duplicação da dívida externa entre 1991-98, quando ela atingiu US\$243,2 bilhões (ver tabela 1).

Em resumo, não é surpreendente que a DMF tenha crescido rapidamente a partir de meados de 1995 (ver Carvalho 1999, Morais 1998 e Rosar 1999). Durante os anos noventa, o governo central tentou controlar o crescimento da DMF principalmente através de cortes de despesas, e superávits fiscais foram atingidos em todos os anos, exceto 1991 (ver tabela 3). Apesar desses superávits, a DMF cresceu US $\$ 39,4$ bilhões em 1995, US $\$ 58,5$ bilhões em 1996, US $\$ 59,0$ bilhões em 1997, e US\$41,0 bilhões em 1998.

As despesas financeiras incluem o custo da DMF e das dívidas contratuais interna e externa do governo central. Fontes: Calculado a partir do Boletim do Banco Central e de dados não-publicados do Tesouro Nacional (detalhes disponíveis aos autores).

A política neomonetarista de taxas de juro permanentemente elevadas subsidiou a acumulação de capital financeiro à custa do capital produtivo e da geração de empregos. Esse processo foi parte da transferência das responsabilidades alocativas, de coordenação econômica e de política industrial do governo federal, para o sistema financeiro, que começou em meados dos anos sessenta e se desenvolveu de forma desigual nas décadas seguintes (Studart 1995). Entretanto, os mercados financeiros no Brasil são geralmente pouco profundos e frágeis, e eles têm sido incapazes de levar adiante essas tarefas sem assistência contínua e substancial do governo.

\footnotetext{
${ }^{10}$ Ver Bacha (1997, p. 190) e Nogueira Batista (1996, p. 56).

${ }^{11}$ Ver Gonçalves (1999a, pp. 106, 134), Cardim de Carvalho (1999) e Studart (1999a, 1999b).
} 
Tabela 3

Brasil: Resultado fiscal e dívida mobiliária federal (DMF), 1991-1998 (US\$ milhões).*

\begin{tabular}{|c|c|c|c|c|c|}
\hline & DMF & $\% \mathrm{PIB}$ & Resultado fiscal & $\%$ PIB & Despesas financeiras \\
\hline 1991 & $16.368,2$ & 4,2 & $-3.596,0$ & $-0,9$ & $19.791,2$ \\
\hline 1992 & $49.169,5$ & 13,1 & $4.305,8$ & 1,2 & $76.314,7$ \\
\hline 1993 & $63.160,5$ & 14,7 & $3.362,6$ & 0,8 & $130.244,9$ \\
\hline 1994 & $73.106,1$ & 13,0 & $9.504,0$ & 1,7 & $123.050,1$ \\
\hline 1995 & $112.536,9$ & 15,7 & $4.899,3$ & 0,7 & $36.165,1$ \\
\hline 1996 & $170.995,6$ & 22,1 & $2.594,8$ & 0,3 & $37.564,0$ \\
\hline 1997 & $229.975,6$ & 28,6 & $16.849,9$ & 2,1 & $44.264,9$ \\
\hline 1998 & $270.921,6$ & 34,9 & $10.734,1$ & 1,4 & $70.996,3$ \\
\hline
\end{tabular}

* Resultado fiscal $=$ receitas menos gastos não-financeiros do Tesouro e da Previdência Social.

As limitações impostas pela crise mexicana sobre a estratégia de acumulação neomonetarista tiveram três efeitos macroeconômicos importantes.

Primeiro, o crescimento acelerado da DMF aumentou as despesas financeiras do governo central, especialmente o pagamento de juros (ver tabela 3). A drenagem de capital produtivo e monetário e salários através do sistema tributário para pagar o serviço da DMF é um reflexo da prioridade financeira das políticas neomonetaristas. Essas políticas tendem a concentrar renda (Bulmer-Thomas 1994, Cepal 1999), e elas reduzem o crescimento de longo prazo (Saad Filho, Morais \& Coelho 1999).

Segundo, o conflito entre as políticas monetárias e fiscais tornou-se cada vez mais severo. Políticas monetárias permanentemente contracionistas tendem a relaxar a política fiscal, porque elas aumentam os custos da DMF e, mais tarde, o estoque da dívida. Para induzir os mercados financeiros a absorver o estoque crescente de títulos públicos, o Tesouro e o Banco Central emitiram títulos cambiais, e eles sancionaram o aumento da liquidez e a redução da maturidade dos títulos da DMF. As crescentes despesas financeiras do governo central, e a crescente liquidez da DMF, induziram as autoridades a contrair sucessivamente as políticas fiscais e monetárias, num círculo vicioso que aumentou a fragilidade financeira do governo central. A solução desse conflito requer o contínuo aumento do superávit fiscal (politicamente impossível), privatizações (limitadas pelos ativos disponíveis) ou, mais realisticamente, a redução das taxas de juro (que pode violar a restrição externa, ver seções 6 e 7).

Terceiro, a discrepância entre as taxas de juro domésticas e internacionais foi uma das causas do aumento mais rápido do passivo externo que dos ativos do governo central. As reservas internacionais cresceram de US\$32,2 bilhões no início de 1994 até um pico de US\$70,9 bilhões no final do primeiro semestre de 1998 $(120,1 \%)$. Neste período, o passivo primário do governo central cresceu de US $\$ 69,8$ bilhões para US $\$ 291,2$ bilhões $(317,2 \%)$. A queda da cobertura de reservas, de $46,1 \%$ do passivo primário para apenas $24,2 \%$, tornou o real mais vulnerável às saídas de capital, apesar do aumento das reservas internacionais (Garcia 1995, 
Nogueira Batista 1996). Em suma, taxas de juro elevadas podem conter temporariamente as saídas de capital, mas elas tendem a aumentar a vulnerabilidade da economia a ataques especulativos. O crescimento acelerado da DMF foi uma das conseqüências mais importantes da estratégia neomonetarista do governo. Seu crescimento foi um sintoma da ineficácia das políticas fiscais e monetárias convencionais, e ele aumentou a fragilidade financeira do Estado e a vulnerabilidade externa da economia.

\section{CRISE CAMBIAL}

A vulnerabilidade externa da economia brasileira tornou o real um alvo natural para ataques especulativos, especialmente depois da crise asiática. O governo brasileiro estava ciente dessa percepção dos mercados, e fez o possível para adiar o desenrolar dos acontecimentos. Sua estratégia centrou-se no oferecimento de oportunidades de hedge aos especuladores através da venda de títulos cambiais e dólar no mercado futuro e, quando necessário, taxas de juro excepcionalmente elevadas. Em outras palavras, o governo estatizou o risco cambial. Entre dezembro de 1997 e dezembro de 1998, o estoque de títulos cambiais cresceu de US\$35,4 bilhões $(15,4 \%$ da DMF) para US\$56,9 bilhões $(21,0 \%)$. Além disso, o Banco Central, operando através da corretora de valores do Banco do Brasil, vendeu US\$15-20 bilhões no mercado futuro de dólares.

As autoridades econômicas aparentemente não perceberam que seu compromisso com a estabilidade cambial e a generosa assistência aos especuladores eram contraproducentes. Após a crise russa, a impressão de que o regime cambial brasileiro era insustentável ganhou credibilidade, levando a uma corrida contra o real. As reservas internacionais caíram de US\$70,9 bilhões em junho de 1998, para apenas US $\$ 33,8$ bilhões nove meses depois (ver tabela 1). Isso deveu-se principalmente aos fluxos de capital de curto prazo e à dificuldade de refinanciar a dívida externa (os fluxos da dívida externa atingiram US $\$ 43,5$ bilhões negativos no período). Nesses três trimestres, o déficit do balanço de pagamentos atingiu US $\$ 46,5$ bilhões, apesar de as taxas reais de juro domésticas se aproximarem de $50 \%$. A DMF desenvolveu um caráter Ponzi, no sentido de que a maturidade dos títulos declinou e seu custo aumentou aceleradamente, em parte devido à percepção do risco de colapso financeiro do governo central.

Nos últimos meses do ano, o governo negociou com o FMI e o G7 um esquema de sustentação financeira no valor de US $\$ 41,3$ bilhões e três anos de duração. Esse acordo foi importante para a comunidade (financeira) internacional, pois ele sinalizou para os mercados que os governos que seguirem as políticas econômicas "corretas" (ou seja, aquelas recomendadas pelo Departamento do Tesouro dos EUA) serão apoiados quando necessário. Domesticamente, o acordo ajudaria a impedir a desvalorização dos capitais domésticos e estrangeiros investidos no Brasil, e preservaria sua capacidade de sair do país. Para garantir esse "direito", o governo brasileiro concordou que o Banco Central deveria manter um piso de US\$20 bilhões nas 
reservas internacionais, exceto recursos do Fundo (esses recursos ficaram indisponíveis para a política cambial, para preservar a possibilidade de fuga de capital).

No final de 1998, o desajuste patrimonial do Estado brasileiro já era gravíssimo. Apesar do superávit fiscal de US $\$ 10,7$ bilhões, a DMF cresceu US $\$ 40,0$ bilhões durante o ano, atingindo US $\$ 270,9$ bilhões em dezembro (34,9\% do PIB). O prazo médio dos títulos caiu para apenas 3,3 meses, e as reservas internacionais declinaram em US\$40 bilhões em seis meses. A acelerada queda das reservas, apesar do aumento da taxa de juros ao limite politicamente possível de 49,8\%, demonstrou o fracasso do neomonetarismo, tanto como estratégia de acumulação, quanto como política de administração da crise.

No início de janeiro de 1999, o governo ampliou a banda de flutuação do real, desvalorizando a moeda em $8 \%$, para $\mathrm{R} \$ 1,32$ por dólar. O colapso cambial foi imediato, forçando o governo a abandonar a sustentação do real. No final do mês, a moeda atingiu $\mathrm{R} \$ 1,98$ por dólar (o real caiu cerca de $40 \%$ em apenas 17 dias).

A desvalorização do real foi diferente das outras crises cambiais nos anos noventa. Estas surpreenderam a maioria dos agentes e desvalorizaram grandes capitais, especialmente no sudeste da Ásia. No Brasil, a iminência do colapso cambial era evidente, e trouxe vultosos ganhos aos grandes capitais, especialmente financeiros. $\mathrm{O}$ impacto da desvalorização sobre a dívida líquida do setor público entre dezembro de 1998 e junho de 1999 foi de R $\$ 43,6$ bilhões ${ }^{12}$; além disso, o Banco Central perdeu cerca de R \$7,8 bilhões no mercado futuro de dólares, elevando o impacto fiscal da desvalorização cambial para 5,6\% do PIB. Em contrapartida, algumas instituições financeiras lucraram, apenas em janeiro, duas vezes mais que em todo o ano anterior ${ }^{13}$. A crise cambial demonstrou que o Brasil tem um Estado previdenciário às avessas, que protege com eficiência os ganhos do capital (especialmente financeiro) à custa dos trabalhadores e, secundariamente, do capital produtivo ${ }^{14}$.

Em março de 1999, o Banco Central introduziu uma política de flutuação controlada da moeda e metas para a inflação, em acordo com o FMI. A flutuação cambial buscou consolidar o aumento da competitividade das exportações e permitir a redução das taxas de juro, para evitar o crescimento explosivo da DMF e permitir a retomada do crescimento econômico.

A nova política cambial estimulou os investidores a executar uma nova manobra especulativa, dessa vez contra o dólar. No final de fevereiro, o real estava claramente subvalorizado a $\mathrm{R} \$ 2,06$ por dólar, mas o Banco Central mantinha os juros

\footnotetext{
12 Boletim do Banco Central, tabela IV.13, dezembro de 1999.

${ }^{13}$ A taxa de lucro bancário no Brasil é geralmente em torno de 11\%. Em janeiro de 1999, vários bancos atingiram taxas de 200-400\%. Os lucros bancários totais em 1998 foram de R $\$ 1,8$ bilhão; no mês de janeiro de 1999, eles atingiram R \$3,3 bilhões (Aloysio Biondi, Folha de S.Paulo, 6/3/99, p. 2-2).

${ }^{14}$ Perguntado por que a queda do real tinha afetado tão pouco o mercado financeiro internacional, o megaespeculador George Soros afirmou que no Brasil a desvalorização tinha sido anunciada, e que havia mecanismos de proteção inexistentes em outros países.
} 
em torno de $40 \%$ apesar do iminente desembolso de US\$4 bilhões pelo FMI. Além disso, o Banco Central ampliou a isenção tributária sobre os ganhos do capital estrangeiro e reduziu o prazo mínimo de investimento no país. Em março, a entrada líquida de capitais para aplicações em títulos e na bolsa de valores atingiu US $\$ 2,7$ bilhões. Esses fluxos apreciaram o real até $\mathrm{R} \$ 1,72$ por dólar, trazendo ganhos de até $20 \%$ em apenas um mês para os especuladores.

O sucesso dessas manobras especulativas, primeiro "a favor" do real (em 199495), depois “contra" (em 1998) e, em seguida, "a favor" (em 1999) demonstram a racionalidade das políticas neomonetaristas no Brasil. A autoridade monetária está fundamentalmente comprometida com os interesses de curto prazo das instituições financeiras privadas. Perdas substanciais de capital serão absorvidas pelo erário, em nome do risco sistêmico, enquanto ganhos de longo prazo são garantidos pelos subsídios financeiros implícitos na política monetária.

\section{PASSOS INCERTOS}

A desvalorização cambial apontou para uma recuperação sustentada baseada em investimentos (principalmente estrangeiros) e nas exportações. O governo, o FMI e seus acólitos no Brasil e no exterior saudaram esses modestos sucessos como se tivessem sido grandes triunfos obtidos sob extrema dificuldade. Essa avaliação não é inteiramente correta, nem pode ser entendida senão à luz dos prognósticos sombrios feitos logo após a desvalorização (inclusive pelos autores deste artigo, Saad Filho, Morais \& Coelho 1999, p. 14). Acreditava-se na época que o PIB contrairia 3-5\% em 1999, e que o desemprego total cresceria rumo a $25 \%$ da força de trabalho. Entretanto, o PIB cresceu $0,8 \%$ (acelerando no ano 2000), e o desemprego manteve-se estável.

A performance brasileira foi bastante distinta de outros países atingidos por crises cambiais. A diferença pode ser explicada em dois níveis. Primeiro, a economia brasileira é relativamente grande e a influência do setor externo ainda é pequena, o que reduz o impacto de uma dada desvalorização relativamente a economias mais abertas. Além disso, a economia brasileira é relativamente integrada e diversificada, incluindo centros industriais avançados, um setor agro-industrial altamente produtivo, e áreas relativamente pobres que fornecem insumos, força de trabalho, mercados e transferências financeiras para os pólos de acumulação de capital. Essa rede de relações produtivas e financeiras é muito resistente e, historicamente, se desenvolveu através de um processo de crescimento de longo prazo bastante dinâmico. Sua notável estabilidade ajudou a moderar o impacto depressivo das políticas neomonetaristas e da crise cambial.

Segundo, a absorção dos custos da crise cambial cambiais pelo governo implicou ganhos substanciais para o setor financeiro e evitou perdas para o grande capital endividado em dólar. A proteção do patrimônio privado e, em muitos casos, a rentabilidade excepcional dos investimentos financeiros gerou recursos que podem ter ajudado a conter a tendência à crise devida à desvalorização do real. Além 
disso, em contraste com a crise da dívida de 1982, os fluxos de capital para o Brasil não se reduziram substancialmente, o que ajudou a sustentar o real entre $\mathrm{R} \$ 1,751,95$ por dólar até, pelo menos, meados de 2000.

É improvável que a política de metas inflacionárias tenha tido qualquer efeito significativo sobre esses eventos. As taxas de juro domésticas foram reduzidas gradualmente após a desvalorização do real até 16,5\% (em meados de 2000), mas isso deveu-se principalmente à conjuntura internacional favorável e à estabilidade do balanço de pagamentos. A economia doméstica, apesar da recuperação, continua deprimida, e precisa de juros menores por longos períodos e políticas industriais ativas como parte das condições necessárias ao crescimento acelerado. Pode-se argumentar que, longe de colher os frutos de sua "prudência" e "credibilidade", o Banco Central tem sido excessivamente tímido. Essa timidez crônica é parte da política neomonetarista de aumentar deliberadamente a influência das finanças especulativas na economia e, mais tarde, justificar essa política através de sua lógica aparentemente inexorável (em outras palavras, a liberalização causa mais liberalização, por razões ideológicas e devido às pressões econômicas geradas pelo próprio processo de liberalização). A verdadeira dimensão da recuperação brasileira e o sucesso das políticas do governo após a desvalorização cambial serão demonstradas apenas quando a economia internacional se defrontar com um novo período de instabilidade. Ausentes desafios substanciais, a amplitude das políticas potencialmente bem-sucedidas é muito grande para permitir a discriminação entre elas.

\section{CONCLUSÃO}

A economia brasileira cresceu pouco, mas mudou muito nos anos noventa. A taxa média de crescimento do PIB durante os anos noventa foi de apenas 1,7\% ao ano, a mais baixa do século, enquanto o desemprego total cresceu de 8 para $17 \%$ da força de trabalho. O emprego industrial caiu em um terço, e a capacidade produtiva declinou em vários setores importantes, especialmente a indústria de bens de capital. A reestruturação industrial reduziu a capacidade da economia de gerar empregos, e o Brasil tornou-se mais dependente de importações e do capital estrangeiro. Por conseqüência, a restrição externa tornou-se mais severa. Os anos noventa foram, sob vários aspectos, piores que a "década perdida" dos oitenta, basicamente devido à virada neomonetarista da política econômica, que foi implementada gradualmente, mas de forma cada vez mais determinada, ao longo da década. Essa mudança presumiu que taxas de juro elevadas e a liberalização comercial e da conta de capitais induziria uma transferência substancial de recursos reais e financeiros ao Brasil, garantindo altas taxas de crescimento por longos períodos.

A experiência do Brasil e de outros países demonstra que as reformas neomonetaristas oferecem uma base inconsistente para a estratégia de desenvolvimento. Elas dependem de variáveis que países como o Brasil influenciam apenas marginalmente, especialmente a disponibilidade e o custo dos recursos financeiros externos. 
Elas modificaram o motor do crescimento rumo ao consumo financiado do exterior e o investimento em bens não-transacionáveis, que reduziu a poupança doméstica, piorou o balanço de pagamentos, e gerou crises fiscais e cambiais. Em conseqüência, a estagnação econômica enraizou-se, e o aumento do desemprego e a deteriora da distribuição de renda neutralizaram os ganhos iniciais com o Plano Real (ver Gonçalves 1999b e Neri \& Considera 1996). Em resumo, a má performance da economia brasileira nos anos noventa se deveu a fatores internos e externos, mas, cada vez mais, ela é conseqüência da imposição de uma estratégia de acumulação que, até agora, foi estável apenas excepcionalmente.

\section{REFERÊNCIAS BIBLIOGRÁFICAS}

ARESTIS, P. \& DEMETRIADES, P. (1999). "Financial Liberalization: The Experience of Developing Countries". Eastern Economic Journal, 25 (4), Fall: 441-457.

ARESTIS, P. \& GLICKMAN, M. (no prelo). "Financial Crisis in South East Asia: Dispelling Illusion the Minskyan Way". Cambridge Journal of Economics.

ARESTIS, P. \& SAWYER, M. (1998). "New Labour, New Monetarism”. Soundings, Summer. Reprinted in European Labour Forum, 20, Winter, 1998-99.

BACHA, Edmar (1997). "Plano Real: Uma Segunda Avaliação”. In: IPEA/CEPAL (orgs.). O Plano Real $e$ Outras Experiências Internacionais de Estabilização. Brasília: IPEA.

BANCO CENTRAL DO BRASIL (1993). O Regime Cambial Brasileiro: Evolução Recente e Perspectivas. Brasília: Banco Central.

BANCO CENTRAL DO BRASIL (1995). Relatório Anual. Brasília: Banco Central.

BARROS, J.R.M. \& ALMEIDA Jr, M. (1997). “Análise do Ajuste do Sistema Financeiro no Brasil”. Política Comparada, 1 (2) Maio-Agosto.

BIRD, G. (1996). "How Important is Sound Domestic Macroeconomics in Attracting Capital Inflows to Developing Countries?”. Journal of International Development, 11: 1-26.

BONELLI, Regis (1999). “A Reestruturação Industrial Brasileira nos Anos 90: Reação Empresarial e Mercado de Trabalho”. In: OIT (ed.). Abertura e Ajuste do Mercado de Trabalho no Brasil. São Paulo: Editora 34.

BONELLI, R. \& GONÇALVES, R. R. (1998). “Para Onde Vai a Estrutura Industrial Brasileira?” In: IPEA (org.). A Economia Brasileira em Perspectiva. Brasília: IPEA.

BRESSER-PEREIRA, L. C. (1981). "A Inflação no Capitalismo de Estado e a Experiência Brasileira Recente". Revista de Economia Política, 1 (2), Abril-Junho.

BRESSER-PEREIRA, L. C. \& NAKANO, Y. (1983). "Fatores Aceleradores, Mantenedores e Sancionadores da Inflação". Anais do X Encontro Nacional da ANPEC.

BRESSER-PEREIRA, L. C. \& NAKANO, Y. (1985). The Theory of Inertial Inflation: The Foundation of Economic Reform in Brazil and Argentina. Boulder: Lynne Rienner.

BRESSER-PEREIRA, L. C. (1996a). Economic Crisis and State Reform in Brazil. London: Lynne Rienner. BRESSER-PEREIRA, L. C. (1996b). “A Inflação Decifrada”. Revista de Economia Política, 16 (4), 64, Outubro-Dezembro.

BULMER-THOMAS, Victor (org.). The New Economic Model in Latin America and its Impact on Income Distribution and Poverty. London: Macmillan.

CALVO, G., LEIDERMAN, L. \& REINHART, C. (1993). "Capital Inflows and Exchange Rate Appreciation in Latin America: The Role of External Factors”. IMF Staff Papers, 40 (1): 108-151.

CALVO, G., LEIDERMAN, L. \& REINHART, C. (1996). "Inflows of Capital to Developing Countries in the 1990s". Journal of Economic Perspectives, 10 (2), Spring: 123-139.

CARDIM DE CARVALHO, Fernando J. (1999). "Sistema Bancário e Competitividade: Efeitos da Pe- 
netração do Capital Estrangeiro no Setor Bancário Brasileiro”. In: C. A. N. Costa \& C.A. Arruda (orgs.). Em Busca do Futuro: A Competitividade no Brasil. Rio de Janeiro: Campus.

CARVAlHO, Carlos E. (1999). As Finanças Públicas no Plano Real. Inédito.

CEPAL (1999). Panorama Social da América Latina, 1998. Nova York: Nações Unidas.

CHANG, Ha-Joon (1994). The Political Economy of Industrial Policy. London: Macmillan.

CHANG, Ha-Joon (1999). Industrial Policy and East Asia: The Miracle, the Crisis, and the Future. Inédito. CNI/CEPAL (1997). Investimentos na Indústria Brasileira 1995-1999 - Características e Determinantes. Rio de Janeiro: CNI.

COUTINHO, L., BALTAR, P. \& CAMARGO, F. (1999). "Desempenho Industrial e do Emprego sob a Política de Estabilização". In: OIT (org.). Abertura e Ajuste do Mercado de Trabalho no Brasil. São Paulo: Editora 34.

CYSNE, Rubens P. (1994). “Imposto Inflacionário e Transferências Inflacionárias no Brasil”. Revista de Economia Política 14 (3), Julho-Setembro.

DORNBUSCH, Rudiger (1997). “Brazil's Incomplete Stabilization and Reform”. Brookings Papers on Economic Activity 1: 367-394.

FEIJÓ, C. A. \& CARVALHO, P. G. M. (1998). Structural Changes in the Brazilian Economy: An Analysis of the Evolution of Industrial Productivity in the 1990s. Inédito.

FINE, B. \& RUSTOMJEE, Z. (1996). The Political Economy of South Africa: From Minerals-Energy Complex to Industrialisation. London: Hurst \& Co.

FINE, B. \& SAAD FILHO, A. (1999). "Políticas Industriais, Finanças e Desenvolvimento: Uma Introdução Crítica à Literatura Recente". Cadernos PUC Economia, 8, Novembro: 49-77.

FIORI, José Luís (1992). "The Political Economy of the Developmentalist State in Brazil”. Cepal Review 47, August: 173-186.

GARCIA, Márcio G. P. (1995). "Política Monetária e Cambial: Algumas Lições do Período 19911994". Estudos Econômicos 25 (3): 329-353.

GONÇALVES, Reinaldo (1999a). Globalização e Desnacionalização. Rio de Janeiro: Paz e Terra.

GONÇALVES, Reinaldo (1999b). "Distribuição de Riqueza e Renda: Alternativa para a Crise Brasileira”. In: Ivo Lesbaupin (ed.). O Desmonte da Nação: Balanço do Governo FHC. Petrópolis: Vozes.

GOVERNO DO BRASIL (1993). Exposição de Motivos no 393 do Ministro da Fazenda. Brasília: Congresso Nacional.

GRABEL, Ilene (2000). “The Political Economy of 'Policy Credibility': The New-Classical Macroeconomics and the Remaking of Emerging Economies". Cambridge Journal of Economics, 24: 1-19.

KILSZTAJN, Samuel (1996). “Ancoragem Cambial e Estabilização”. In: R. R. Sawaya (org.). O Plano Real e a Política Econômica. São Paulo: Educ.

LAPLANE, M.F. \& SARTI, F. (1999). "O Investimento Direto Estrangeiro no Brasil nos Anos 90: Determinantes e Estratégias”. In: D. Chudnovsky (ed.). Investimentos Externos no Mercosul. Campinas: Papirus.

MOLLO, Maria L.R. \& SAAD FILHO, A. (2001). "Reconhecimento Social da Moeda: Observações Sobre a Inflação e a Estabilização de Preços no Brasil” Revista de Economia Política, 21 (2), AbriIJunho.

MORAIS, Lecio (1998). “A Crise Brasileira, a Dívida e o Déficit Públicos: para que Superávit Fiscal?”. Princípios, agosto.

NEMBHARD, Jessica G. (1996). Capital Control, Financial Regulation, and Industrial Policy in South Korea and Brazil. Westport, Conn.: Praeger.

NERI, Marcelo \& CONSIDERA, Claudio (1996). "Crescimento, Desigualdade e Pobreza: O Impacto da Estabilização”. In: IPEA (org.). A Economia Brasileira em Perspectiva. Brasília: IPEA.

NOGUEIRA BATISTA Jr., Paulo (1996). "Plano Real: Estabilização Monetária e Desequilíbrio Externo". Cadernos Temáticos, 2, Sindicato dos Engenheiros do Rio de Janeiro.

PAES DE BARROS, R., CAMARGO, J. M. \& MENDONÇA, R. (1998). "A Estrutura do Desemprego no Brasil”. In: IPEA (org.). A Economia Brasileira em Perspectiva. Brasília: IPEA.

PALLEY, Thomas I. (2000). Escaping the "Policy Credibility" Trap: International Financial Markets and Socially Responsive Macroeconomic Policy. Inédito. 
PALMA, Gabriel (1998). “Three and a Half Cycles of 'Mania, Panic and [Asymmetric] Crash': East Asia and Latin America Compared". Cambridge Journal of Economics, 22 (6), November: 789 808.

POCHMANN, Marcio (1999). O Trabalho sob Fogo Cruzado: Exclusão, Desemprego e Precarização no Final do Século. São Paulo: Contexto.

RADICE, Hugo (1998). “'Globalization' and National Differences”. Competition \& Change, 3: 263291.

RADICE, Hugo (1999). “Taking Globalisation Seriously”. Socialist Register,: 1-28.

RAMOS, L. \& ALMEIDA REIS, J. G. (1998). “Emprego no Brasil nos Anos 90”. In: IPEA (ed.) A Economia Brasileira em Perspectiva. Brasília: IPEA.

RODRIK, Dani (1998). "Globalisation, Social Conflict and Economic Growth”. The World Economy, 21 (1), March: 143-158.

ROSAR, Orlando Oscar (1999). "Considerações Sobre a Evolução da Dívida Pública Brasileira nas Últimas Três Décadas”. Anais do IV Encontro Nacional de Economia Política, Porto Alegre.

SAAD FILHO, A. \& MORAIS, L. (2000). "The Costs of Neomonetarism: The Brazilian Economy in the 1990s". International Papers in Political Economy. December.

SAAD FILHO, A., MORAIS, L. \& COELHO, W. (1999). "Financial Liberalization, Currency Instability and Crisis in Brazil: Another Plan Bites the Dust". Capital \& Class 68, Summer 1999: 9-14.

SAAD FILHO, A. \& MALDONADO FILHO, E. (1998). "Políticas Econômicas no Brasil: Da Heterodoxia ao Neomonetarismo". Indicadores Econômicos 21, Setembro.

STUDART, Rogério (1995). Investment Finance in Economic Development. London: Routledge.

STUDART, Rogério (1999a). Estrutura e Operação dos Sistemas Financeiros no Mercosul: Perspectivas a Partir das Reformas Institucionais dos Anos 1990 e para a Integração Financeira das Economias do Bloco. Relatório Cepal/IPEA/IE-UFRJ.

STUDART, Rogério (1999b). Financial Opening and Deregulation of Brazil's Financial Systems in the 1990s: Possible Effects on its Pattern of Development Financing. Inédito.

URANI, André (1998). "Ajuste Macroeconômico e Flexibilidade do Mercado de Trabalho no Brasil: 1981/95”. In: IPEA (org.). A Economia Brasileira em Perspectiva. Brasília: IPEA. 